\title{
Affective Temperament is Associated with Stress Coping Strategies and Work Stress Perception Among Polish Bank Employees
}

This article was published in the following Dove Press journal: Psychology Research and Behavior Management

\author{
Katarzyna Białczyk' \\ Zofia Wyszkowska' \\ Maciej Bieliński $\mathbb{D}^{2}$ \\ 'Health Economy Division, Collegium \\ Medicum in Bydgoszcz, Nicolaus \\ Copernicus University in Torun, \\ Bydgoszcz, Poland; ${ }^{2}$ Department of \\ Clinical Neuropsychology, Collegium \\ Medicum in Bydgoszcz, Nicolaus \\ Copernicus University in Torun, \\ Bydgoszcz, Poland
}

Background: Stress in the banking workplace is associated with psychological and health problems. Intensity of work-related stress experiences is associated with specificity of job stress factors personal features such as affective temperament. The aim of the study was to evaluate associations between affective temperament, coping stress strategies, and perceived job stress in bank employees.

Methods: Subjects were 209 bank workers aged 22-55 years $(n=101$ managers and 108 non-managers). Affective temperament and stress coping strategies were evaluated using the Temperament Evaluation of Pisa, Paris and San Diego Autoquestionnaire (TEMPS-A) and Coping Inventory for Stressful Situations (CISS), respectively. Both questionnaires, TEMPSA and CISS, show good internal consistency and are proper research methods in the bank employee group. Perceived job-related stress was rated for different sources of job stress common among bank workers.

Results: Depressive temperament was negatively associated with coping style focused on avoidance, and with job stress regarding "responsibility for decisions regarding other people" and "frequent trips." Irritable temperament was positively correlated with coping style focused on task and job stress regarding "frequent trips." Cyclothymic temperament was positively correlated with job stress regarding "direct work with money" and "organizational conditions of work." Multidimensional linear regression showed that irritable and anxious temperaments were associated with coping style focused on task; depressive temperament was associated with coping style focused on avoidance; and cyclothymic temperament was associated with intensity of job stress. The results obtained indicate different levels of jobrelated stress associated with different sources in bank employees, working with managers and non-managers positions. Affective temperament was associated with stress coping strategies and intensity of perceived job stress. On the basis of affective temperament dimensions it is possible to predict stress coping styles and work-related stress perception in bank employees.

Conclusion: Affective temperament traits measured by TEMPS-A were associated with stress coping strategies and intensity of work stress perception in Polish bank employees.

Keywords: affective temperament, stress coping, work stress perception, bank employee

\section{Introduction}

High stress at work may influence health condition, work effectiveness, and quality of daily functioning in different workers' groups. ${ }^{1-5}$ The health consequences of occupational stress are associated with large economic and social costs. ${ }^{6,7}$ The changes that took place in the financial markets during the $2007-08$ crisis caused Medicum in Bydgoszcz, Nicollegus

Copernicus University in Torun Sandomierska, St. 16, 85-830, Bydgoszcz, Poland

Tel/Fax +48525855409

Email katarzyna.bialczyk@cm.umk.pl 
deterioration in the organization of and working conditions in the banking sector. There were mergers of banks and significant organizational changes that resulted in fewer employees, changes in the roles of employees, and changes in the terms of employment contracts, eg, accumulation of new tasks. ${ }^{8,9}$ These rapid and sizeable changes applied to both managers and non-managers, and worsened interpersonal communication, lowering the sense of personal safety and stability of work. ${ }^{10,11}$

A meta-analysis of 20 papers showed that stress in the banking workplace was at a critical level and was connected with serious stress-related psychological and health problems, such as maladaptive behavior, anxiety and depression, and burnout syndrome. ${ }^{12}$ Among bank workers, the prevalence of depressive and anxiety symptoms is very high. Mannocci et al showed that $82 \%$ of Italian bank workers were anxious about the failure to reach set goals, $84 \%$ had discomfort while recommending customers a product just because it was in their budget goal, $64 \%$ felt pressure to sell, and $63 \%$ had been urged by their superior to be "elastic" in performing their duties. ${ }^{13}$

Intensity of perceived job stress is conditioned by many factors, including the specificity of the work, personality traits, and affective temperament dimensions. ${ }^{14-16}$ The contemporary concept of affective temperament was developed by American psychiatrist Hagop Akiskal. ${ }^{17,18}$ Affective temperament is relatively stable and genetically conditioned.

According to Akiskal's theory, the configuration of the five dimensions of affective temperament (depressive, cyclothymic, hyperthymic, irritable, and anxious) is determined by emotional reactivity, stress sensitivity, and styles of human emotional reactions. Specific configuration temperament traits may be associated with predisposition to psychiatric, mainly affective, disorders. ${ }^{19-22}$

Affective temperament has been related to intensity of perceived job-related stress. ${ }^{23}$ A study performed in Japan showed that depressive and anxious dimensions of affective temperament were associated with higher sensitivity for job stress factors and risk of depression, whereas the hyperthymic dimension was protective. ${ }^{15}$ Deguchi et al found a strong correlation between affective temperament and work stress perception in government administration workers. ${ }^{24}$

Similar results were obtained by Polish authors who found a relationship between the depressive and anxiety dimensions and a higher risk of burnout syndrome and poorer health condition in nurses and civil servants. ${ }^{16}$ Stress coping is defined as the process by which a person manages stress. ${ }^{25}$ In stressful situations people use different coping strategies, eg, concentration on task, on problem solving, on emotion or on avoidance. Adaptive coping strategies may decrease the intensity of situational stress and minimalize the risk of stress consequences, like behavioral and psychological dysfunctions, anxiety, depression, and burnout. Data obtained by Viana Machado et al indicate that lower levels of adaptive and higher levels of dysfunctional coping styles are associated with severity of posttraumatic stress symptoms in college students. ${ }^{26}$ McKinley et al reported high prevalence of burnout and maladaptive stress coping strategies of selfdistraction in medical doctors in UK. ${ }^{27}$ Another study involving 464 bank employees showed direct action of coping on well-being, however palliative coping was predictive of higher levels of psychological distress and psychosomatic complaints. Interestingly, no association between coping strategies and job satisfaction were observed. ${ }^{28}$

The purpose of this cross-sectional study was to evaluate the possible relationships between the five dimensions of affective temperament and stress coping styles, and intensity of perceived job stress connected with different sources in Polish bank employees in the Kuyavian Pomeranian region working in managerial and nonmanagerial positions. Considering the fact that managerial work requires interpersonal and communication abilities, and the ability to make optimal decisions (with financial and human responsibility), we hypothesized that scores for hyperthymic temperament and coping style focused on task would be higher among managers than nonmanagers. We also expected that affective temperament dimensions would be associated with stress coping strategies and intensity of perceived of job-related stress.

\section{Methods}

Our cross-sectional study received approval from the Bioethics Committee of the Nicolaus Copernicus University in Torun, Collegium Medicum in Bydgoszcz, Poland (Ref. No KB 334/2017). Information about the purpose and procedure of the study was distributed in the Polish banks offices. Persons who expressed their willingness to participate in the study were handed a set of study questionnaires and instructed to return the completed questionnaires to a box. Following the agreement of the Bioethics Committee at the Nicolaus Copernicus University, researchers and bank management, the study was conducted with complete anonymity of the participants and, in line with the Bioethics Committee's consent, 
the collection of informed consent forms was not performed. The paper does not contain patient identifiable features. The study was conducted in accordance with the Declaration of Helsinki.

\section{Subjects}

A total of 300 sets of questionnaires were delivered and 256 of these were returned. Overall, 47 sets of incomplete questionnaires were removed from the data analysis. The remaining 209 sets of questionnaires were included in the final analysis.

The investigated group comprised 209 bank workers (99 males and 110 females) aged 22-55 years (mean age 35.5 SD 6.5 years). The mean number of years of education was 16.03 SD 5.4 years. The highest level of education achieved was secondary school for 12 subjects, and greater than secondary school for 197 subjects. There was no difference in age, duration of work experience, or duration in current position between males and females. A total of 101 subjects working as advisers were placed in the managers group (MG; 49 females and 52 males), and 108 subjects working as cashiers were placed in the nonmanagers group (NMG, 61 females and 47 males). The duration of total professional work was $13.3 \pm 6.4$ years in the MG group and 10.2 \pm 5.7 years in the NMG group ( $p=$ 0.004, Mann-Whitney U-test).

However, the duration of work on the current position was similar in the two groups $(6.0 \pm 3.7$ years and $5.9 \pm$ 3.7 years in MG and NMG groups, respectively, $p=0.63$, Mann-Whitney U-test).

\section{Outcome Variables}

For evaluation of job-related perceived distress, we designed the 14-item self-reported questionnaire. The 14 questions were selected from the 30 -items listed by four experts - competent judges - on the base on judge compliance coefficient (up to 85\%). The one general question was: „How do you rate your job stress in relationship to the following factors?". The participants were asked to answer that question in relationship to the following stressors: 1) financial responsibility for decisions; 2) responsibility for decisions regarding other people; 3) working under pressure; 4) frequent changes to the terms of the employment contract (annexes); 5) frequent trips; 6) unpredictable end of work time; 7) direct work with money; 8) direct contact with clients; 9) interpersonal workplace conflicts; 10) conflict of interests between workers; 11) organizational conditions of work; 12) uncertainty of earnings; 13) the necessity of reporting the completed sales plan; and 14) fear of losing a job or changing job position. The subjects rated their responses on a $0-7$ scale, with " 0 " indicating no stress and " 7 " indicating maximal level of stress. The questionnaire showed good internal consistency, Cronbach's alpha was 0.78 .

Affective temperament was evaluated using the Polish version of the 110-item Temperament Evaluation of Pisa, Paris and San Diego Autoquestionnaire (TEMPS-A). ${ }^{18,29}$ TEMPS-A questionnaire is a self-assessment scale for evaluation of five dimensions of affective temperament: depressive (D), cyclothymic (C), hyperthymic (H) irritable (I), and anxious (A). "D" temperament describes people who are pessimistic, given to worry, guilt-prone, conscientious and self-disciplining, skeptical, gloomy, difficulties in ability to experience joy, preoccupied with inadequacy, failure and negative events. " $\mathrm{C}$ " temperament described persons with labile self-esteem, overconfidence alternating with low selfconfidence, alternating periods of unusually high and low professional and creative productivity, unexplained tearfulness alternating with extreme joyfulness. " $\mathrm{H}$ " temperament predicted openness, high activity, leadership, risk-behaviors, stress resistance, grandiosity, and seeking extreme stimuli. "I" temperament manifests itself in restless, dysphoric, broody and explosive reactions. "A" temperament indicates worry about mundane matters, preoccupation with possible or present external dangers to oneself of one's relatives, and taking care of others as well. ${ }^{15,17,18}$

\section{Statistical Analysis}

The distribution of each variable was checked using the Shapiro-Wilk test. The criteria for normality were not met, therefore non-parametric tests were used. Two groups were compared using a Mann-Whitney U-test, and more than two groups were compared using the Kruskal-Wallis analysis of variance. Correlations between variables were assessed using Spearman's rho coefficient. The internal consistency of TEMPS-A was evaluated using the Kuder-Richardson 20, and that of CISS was evaluated using Cronbach's alpha. Multidimensional linear regression was used to evaluate the association between the dimensions of affective temperament (evaluated using TEMPS-A), and job stress and coping styles (evaluated using CISS).

\section{Results}

The results of TEMPS-A and CISS are shown in Table 2. For TEMPS-A, the highest score was for " $H$ " temperament, 
Table I Reliability Coefficients and Results of the Principal Component Analysis of TEMPS-A and CISS

\begin{tabular}{|c|c|c|c|}
\hline & \multirow[t]{2}{*}{$\begin{array}{l}\text { Reliability } \\
\text { Coefficient }\end{array}$} & \multicolumn{2}{|c|}{$\begin{array}{l}\text { Principal Component } \\
\text { Analysis }\end{array}$} \\
\hline & & Factor I & Factor II \\
\hline \multicolumn{4}{|l|}{ TEMPS-A } \\
\hline Depressive & 0.68 & -0.74 & 0.12 \\
\hline Cyclothymic & 0.70 & 0.03 & -0.63 \\
\hline Hyperthymic & 0.79 & 0.65 & 0.11 \\
\hline Irritable & 0.72 & 0.03 & -0.82 \\
\hline Anxious & 0.82 & -0.81 & -0.31 \\
\hline \multicolumn{4}{|l|}{ CISS } \\
\hline SFT & 0.72 & -0.28 & 0.75 \\
\hline SFE & 0.65 & -0.48 & -0.53 \\
\hline SFA & 0.86 & -0.97 & -0.02 \\
\hline$A C Z$ & & -0.83 & -0.39 \\
\hline PKT & & -0.61 & 0.64 \\
\hline
\end{tabular}

Note: The reliability coefficient is Kuder-Richardson 20 for TEMPS-A and Cronbach's alpha for CISS.

Abbreviations: CISS, Coping Inventory for Stressful Situations; SFA, style focused on avoidance; SFE, style focused on emotions; SFT, style focused on task; TEMPS-A, Temperament Evaluation of Pisa, Paris and San Diego Autoquestionnaire.

and then, in descending order, "D", "C", and "I." Females scored higher than males for "I" and "A" temperaments, whereas males scored higher for " $\mathrm{H}$ " ones. MG scored higher than NMG for "H" temperament and lower for coping style "SFE." There were no significant differences between males and females in coping styles. Intensity of job stress associated with different sources is presented in Table 3. Job stress regarding "responsibility for decisions regarding other people" and "frequent trips" was greater in the MG group than in the NMG group, whereas job stress regarding "work under pressure," "frequent changes to the terms of the employment contract" (annexes), "unpredictable end of work time," "direct contact with clients," and "conflict of interests between workers" was greater in the NMG group. Total job stress was greater in the NMG group than in the MG group. There were no differences in job stress between males and females. " $D$ " temperament in TEMPS negatively correlated with "SFA" (engaging in substitute activities substyle; $\mathrm{R}=-0.17 ; p=0013$ ) in the CISS questionnaire, and the correlation coefficient was greater in women $(\mathrm{R}=-0.27 ; p=0.004)$ than in men. "D" temperament was also negatively correlated with job stress associated with "responsibility for decisions regarding other people" $(\mathrm{R}=-0.14 ; p=0.04)$ and "frequent trips" $(\mathrm{R}=-0.16 ; p=0.02)$. " $\mathrm{C}$ " temperament was positively correlated with job stress regarding "direct work with money" $(\mathrm{R}=0.23 ; p<0.001)$ and "organizational conditions of work" $(\mathrm{R}=0.17 ; p=0.013)$. "I" temperament was positively correlated with "SFT" $(\mathrm{R}=0.15 ; p=0.03)$ and job stress regarding "frequent trips" $(\mathrm{R}=0.15 ; p=0.03)$. Multidimensional linear regression analysis was used to assess the associations between the dimensions of affective

Table 2 Affective Temperament and Coping Styles

\begin{tabular}{|c|c|c|c|c|c|}
\hline & Whole Group N = 209 & Males $=99$ & Females $\mathrm{n}=1 \mathrm{I} 0$ & $M G n=|0|$ & NMG $n=108$ \\
\hline \multicolumn{6}{|l|}{ TEMPS-A } \\
\hline Depressive & $0.26 ; 0.24-0,33$ & $0.29 ; 0.24-0.33$ & $0.29 ; 0.19-0.33$ & 0,$29 ; 0.24-0.33$ & 0,$29 ; 0.24-0.33$ \\
\hline Cyclothymic & $0.26 ; 0.19-0,33$ & $0.24 ; 0.19-0.33$ & $0.29 ; 0.19-0.33$ & 0,$29 ; 0.19-0.38$ & 0,$24 ; 0.19-0.38$ \\
\hline Hyperthymic & $0.62 ; 0.52-0.71$ & $0.62 ; 0.57-0.7 \mathrm{I}$ & $0.57 ; 0.48-0.67^{*}$ & $0.64 ; 0.57-0.7 \mid$ & $0.57 ; 0.57-0.7 \mathrm{I} \#$ \\
\hline Irritable & $0.10 ; 0.10-0.19$ & $0.10 ; 0.05-0.15$ & $0.14 ; 0.10-0.19 *$ & $0.14 ; 0.07-0.19$ & $0.10 ; 0.07-0.19$ \\
\hline Anxious & $0.23 ; 0.15-0.27$ & $0.19 ; 0.15-0.23$ & $0.23 ; 0.19-0.31 * *$ & $0.23 ; 0.15-0.27$ & $0.19 ; 0.15-0.27$ \\
\hline \multicolumn{6}{|l|}{ CISS } \\
\hline SFT & $3.88 ; 3.69-4.13$ & $3.94 ; 3.69-4.12$ & $3.88 ; 3.63-4.19$ & $3.94 ; 3.69-4.16$ & $3.88 ; 3.69-4.16$ \\
\hline SFE & $2.5 ; 2.31-2.69$ & $2.44 ; 2.22-2.69$ & $2.50 ; 2.31-2.75$ & $2.44 ; 2.25-2.63$ & $2.56 ; 2.31-2.75 \#$ \\
\hline SFA & $2.94 ; 2.69-3.19$ & $3.00 ; 2.69-3.16$ & $2.94 ; 2.75-3.19$ & $2.94 ; 2.63-3.16$ & $3.00 ; 2.75-3.19$ \\
\hline
\end{tabular}

Notes: Values are median; 25 th-75th percentile. ${ }^{*} p<0.01$ and ${ }^{* *} p<0.001$ compared with males. ${ }^{*} p<0.05$ compared with MG. Mann-Whitney U-test. Abbreviations: CISS, Coping Inventory for Stressful Situations; MG, management group; NMG, non-management group; SFT, style focused on task; SFE, style focused on emotions; SFA, style focused on avoidance TEMPS-A, Temperament Evaluation of Pisa, Paris and San Diego Autoquestionnaire. 
Table 3 Intensity of Perceived Work-Related Stress in Managers and Non-Managers

\begin{tabular}{|c|c|c|c|}
\hline Source & Whole Group N = 209 & $M G n=101$ & NMG $n=108$ \\
\hline Financial responsibility for decisions & $5.54 \pm 1.36$ & $5.52 \pm 1.25$ & $5.55 \pm 1.46$ \\
\hline Responsibility for decisions regarding other people & $3.21 \pm 2.96$ & $5.67 \pm 1.58$ & $0.88 \pm 1.89 * *$ \\
\hline Working under pressure & $5.60 \pm 1.22$ & $4.92 \pm 1.07$ & $6.23 \pm 0.99 * *$ \\
\hline Frequent changes to the terms of the employment contract (annexes) & $3.85 \pm 2.05$ & $2.58 \pm 1.46$ & $5.06 \pm 1.78 * *$ \\
\hline Frequent trips & $3.83 \pm 2.00$ & $5.04 \pm 1.75$ & $2.68 \pm 1.50 * *$ \\
\hline Unpredictable end of work time & $4.56 \pm 2.11$ & $3.69 \pm 2.06$ & $5.40 \pm 1.80 * *$ \\
\hline Direct work with money & $3.04 \pm 3.03$ & $0.67 \pm 1.73$ & $5.33 \pm 2.08^{* *}$ \\
\hline Direct contact with clients & $3.98 \pm 2.11$ & $2.67 \pm 1.90$ & $5.24 \pm 1.44 * *$ \\
\hline Interpersonal workplace conflicts & $5.12 \pm 1.62$ & $4.98 \pm 1.69$ & $5.26 \pm 1.55$ \\
\hline Conflict of interests between workers & $4.53 \pm 1.89$ & $4.15 \pm 1.93$ & $4.90 \pm 1.77^{*}$ \\
\hline Organizational conditions of work & $4.07 \pm 2.07$ & $4.01 \pm 2.09$ & $4.13 \pm 2.06$ \\
\hline Uncertainty of earnings & $5.22 \pm 1.81$ & $5.16 \pm 1.79$ & $5.28 \pm 1.83$ \\
\hline The necessity of reporting the completed sales plan & $4.90 \pm 1.77$ & $4.77 \pm 1.76$ & $5.03 \pm 1.79$ \\
\hline Fear of losing a job or changing job position & $5.69 \pm 1.29$ & $5.68 \pm 1.37$ & $5.69 \pm 1.21$ \\
\hline Total score & $4.51 \pm 0.81$ & $4.25 \pm 0.76$ & $4.76 \pm 0.77 * *$ \\
\hline
\end{tabular}

Notes: Values are mean \pm standard deviation. ${ }^{*} p<0.01$ and ${ }^{* *} p<0.0001$ compared with MG. Mann-Whitney U-test.

temperament and stress coping styles and job stress (Table 4). The results indicated that "I" temperament was positively associated with "SFT" in CISS, and "A" temperament was negatively associated with "SFT." The regression equation (with estimation errors in parentheses) was as follows:

SFT $=0.82 \cdot$ "I" temperament - 0.63 " $\mathrm{A}$ " temperament (0.30) (0.31)

"D" temperament was associated with CISS-SFA, and "C" temperament with intensity of overall job stress perception (OJSP). The residual normality graphs for the regression model for CISS-SFT, CISS-SFA, and OJSP are shown in Figure 1. In order to illustrate the postulated model describing the relationship among affective temperament, stress coping strategies and perceived workrelated stress, a graphic was prepared (Figure 2).

\section{Discussion}

In this cross-sectional study, we examined affective temperament among bank employees in relation to stress coping styles and job-related stress. TEMPS-A is commonly used for evaluation of affective temperament dimensions in clinical subgroups and in healthy subjects, ${ }^{16,29,31}$ and
CISS is an accepted tool for studying stress management strategies in different clinical groups. ${ }^{32-34}$ Both questionnaires had good internal consistency in the current study.

Our results indicated that hyperthymic temperament measured by TEMPS A was explained by a different pathogenetic mechanism compared with other dimensions of temperament. This confirms the results of a previous study performed in a Polish sample. ${ }^{29}$ A coping style focused on task, which is a constructive way of dealing with stress, was associated with different factors than negative stress coping styles focused on emotions and avoidance. In the study group the most prevalent temperament was hyperthymic, which confirms previous observations in other worker groups. Hyperthymic temperament is associated with openness, ability to work under time and psychological pressure, and better functioning in stressful work situations. ${ }^{16,24}$ As we predicted, the most common coping style was focused on task, which is connected with ability to constructive problem solving, and to reasonable planning as well. Managers obtained a higher score for hyperthymic temperament and a lower score for style focused on emotions than nonmanagers. This supports similar results obtained in 
Table 4 Associations Between the Dimensions of Affective Temperament and Coping Styles and General Perception of Work Stress $(\mathrm{N}=209)$

\begin{tabular}{|c|c|c|c|c|c|c|}
\hline & \multicolumn{6}{|c|}{$\begin{array}{l}\text { Regression Summary for Dependent Variable: Coping Style Focused on Task, } \\
R=0.3003438 \text { I; } R^{2}=0.09020640 ; \text { Adjusted } \mathbf{R}^{2}=\mathbf{0 . 0 6 6 3 8 9 8 2} \\
F(5|9|)=3.7875 ; p=0.0027 \text { I; Std. Error of Estimate: } 0.36994\end{array}$} \\
\hline & $\beta$ & Std. Error of $\beta$ & $b$ & St. Error of $b$ & $t(191)$ & $p$-value \\
\hline Intercept & & & 3.793 & $0.17 \mid$ & 22.146 & 0.0000 \\
\hline TEMPS-D & -0.033 & 0.077 & -0.139 & 0.323 & -0.430 & 0.667 \\
\hline TEMPS-C & 0.040 & 0.070 & 0.122 & 0.256 & 0.567 & $0.57 I$ \\
\hline TEMPS-H & 0.096 & 0.073 & 0.234 & 0.179 & 1.306 & 0.193 \\
\hline TEMPS-I & 0.201 & 0.074 & 0.821 & 0.303 & 2.713 & 0.007 \\
\hline \multirow[t]{3}{*}{ TEMPS-A } & -0.162 & 0.081 & -0.631 & 0.314 & -2.011 & 0.046 \\
\hline & \multicolumn{6}{|c|}{$\begin{array}{l}\text { Regression Summary for Dependent Variable: Style Focused o Avoidance } \\
R=0.26693473 ; R^{2}=0.07|254| 5 ; \text { Adjusted } \mathbf{R}^{2}=\mathbf{0 . 0 4 6 9 4 | 4 3} \\
F(5|9|)=2.9307 ; p=0.0 \mid 422 ; \text { Std. Error of Estimate: } 0.39747\end{array}$} \\
\hline & $\beta$ & Std. Error of $\beta$ & $\mathbf{b}$ & St. Error of b & $t(191)$ & $\boldsymbol{p}$-value \\
\hline Intercept & & & 3.097 & 0.184 & 16.828 & 0.0000 \\
\hline TEMPS-D & -0.177 & 0.078 & -0.791 & 0.348 & -2.274 & 0.024 \\
\hline TEMPS-C & 0.128 & 0.071 & 0.421 & 0.232 & 1.819 & 0.071 \\
\hline TEMPS-H & 0.009 & 0.074 & 0.024 & 0.193 & 0.125 & 0.901 \\
\hline TEMPS-I & 0.036 & 0.075 & 0.155 & 0.325 & 0.478 & 0.633 \\
\hline \multirow[t]{3}{*}{ TEMPS-A } & -0.077 & 0.082 & -0.319 & 0.337 & -0.947 & 0.345 \\
\hline & \multicolumn{6}{|c|}{ 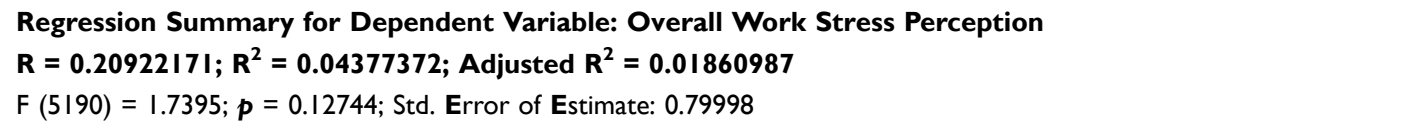 } \\
\hline & $\boldsymbol{\beta}$ & Std. Error of $\beta$ & b & Std. Error of $b$ & $t(191)$ & $p$-value \\
\hline Intercept & & & 3.391 & 0.371 & 10.607 & 0.0000 \\
\hline TEMPS-D & 0.104 & 0.079 & 0.924 & 0.704 & 1.133 & 0.191 \\
\hline TEMPS-C & 0.154 & 0.072 & 1.003 & 0.467 & 2.148 & 0.033 \\
\hline TEMPS-H & 0.026 & 0.076 & 0.132 & 0.388 & 0.340 & 0.734 \\
\hline TEMPS-I & 0.106 & 0.076 & 0.910 & 0.654 & 1.390 & 0.166 \\
\hline TEMPS-A & -0.090 & 0.083 & -0.738 & $0.68 I$ & -1.083 & 0.280 \\
\hline
\end{tabular}

medical emergency professionals, nurses, and civil servants. ${ }^{16,35}$ Females scored higher on irritable and anxious temperaments compared to males. This does not fully correspond with another study of healthy Polish subjects that showed higher depressive temperament in women and higher irritable temperament in men. ${ }^{29}$ Also, Rihmer et al suggested that depressive, cyclothymic, and anxious temperaments were more prevalent among women, whereas hyperthymic and irritable temperaments were more prevalent among men. ${ }^{36}$

Among managers, the greatest job stress was associated with "responsibility for decisions regarding the other people" and "frequent trips." Among nonmanagers, the greatest job stress was associated with 
A

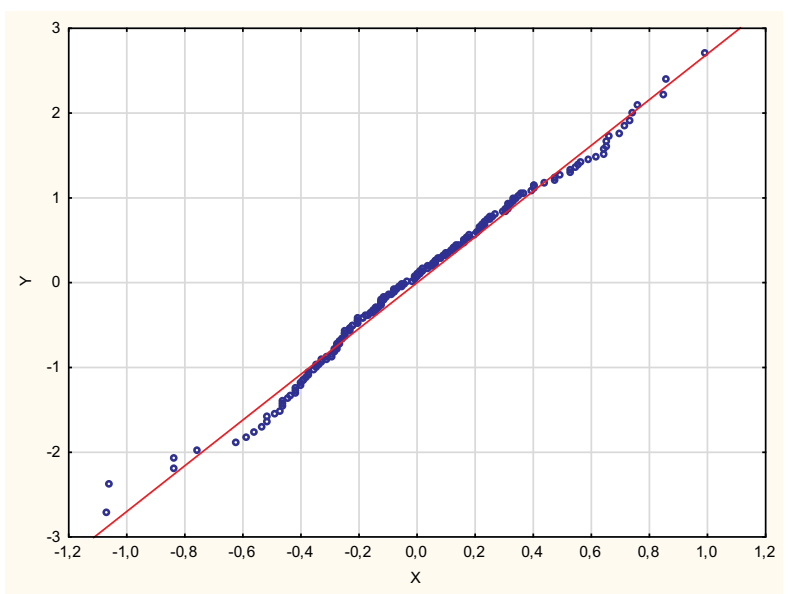

B

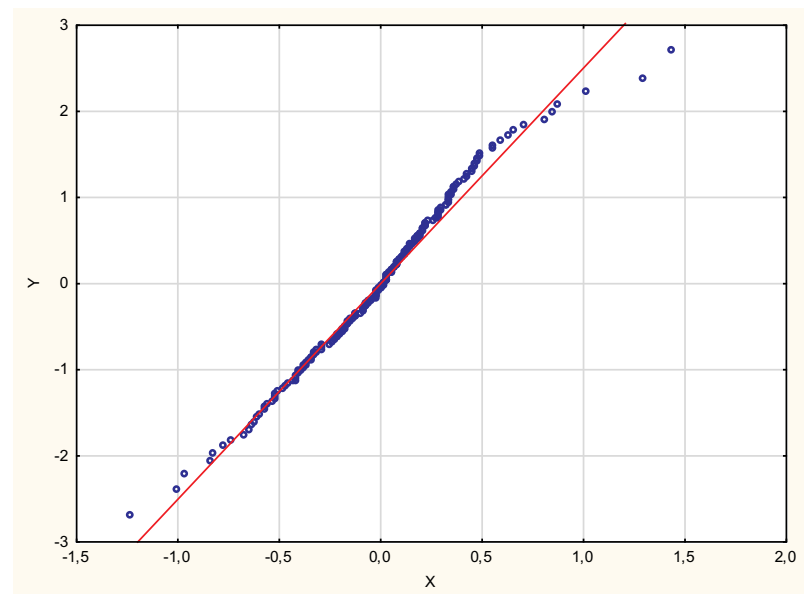

C

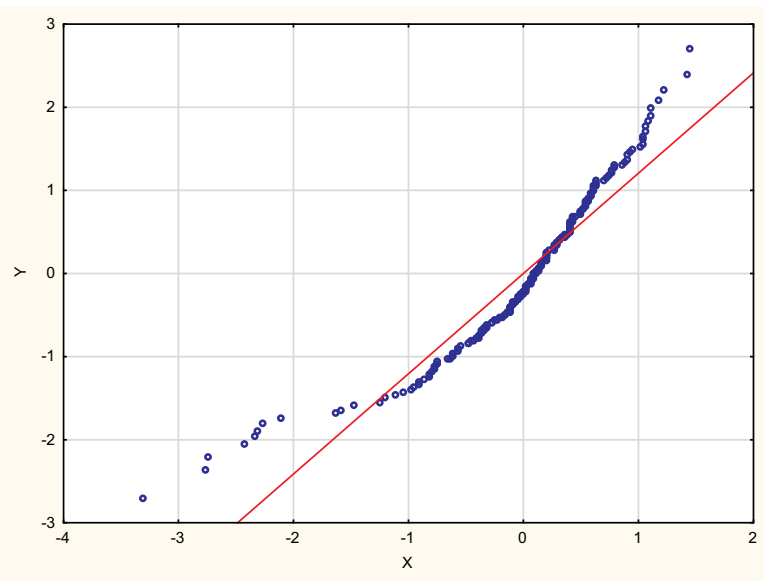

Figure I Residual normality plots; (A) residual normality plots of coping style focused on task; (B) residual normality plots of coping style focused on avoidance; (C) residual normality plots of overall job stress perception.

"work under pressure," "frequent changes to the terms of the employment contract," "unpredictable end of work time," "direct contact with clients", and "conflict of interests between workers." This indicates different sources of work-related stress which are important for people working in different positions in banks.

Analysis of correlation between affective temperament dimensions and stress coping strategies showed a negative association between depressive temperament and coping style focused on avoidance, and between depressive temperament and job stress regarding "responsibility for decisions regarding other people" and "frequent trips." Cyclothymic dimension was correlated with intensity of stress perception regarding "direct work with money" and "organizational conditions of work." Irritable temperament revealed association with style focused on task. Deguchi et al obtained similar results, reporting that irritable temperament was associated with perception of low support from managers and coworkers and high sensitivity to interpersonal conflict at the workplace, while anxious temperament was associated with perception of low support from managers and coworkers, and high fear of job loss. ${ }^{24}$ They also found that hyperthymic temperament was associated with better job control, better ability to make decisions and manage job tasks, and lower general perception of job stress. The present study performed in bank workers does not fully confirm these results. We did not find a significant association between hyperthymic temperament and stress coping strategies or job-related stress perception.

Our observations were reinforced by the multidimensional linear regression analysis (MLR). We found that 


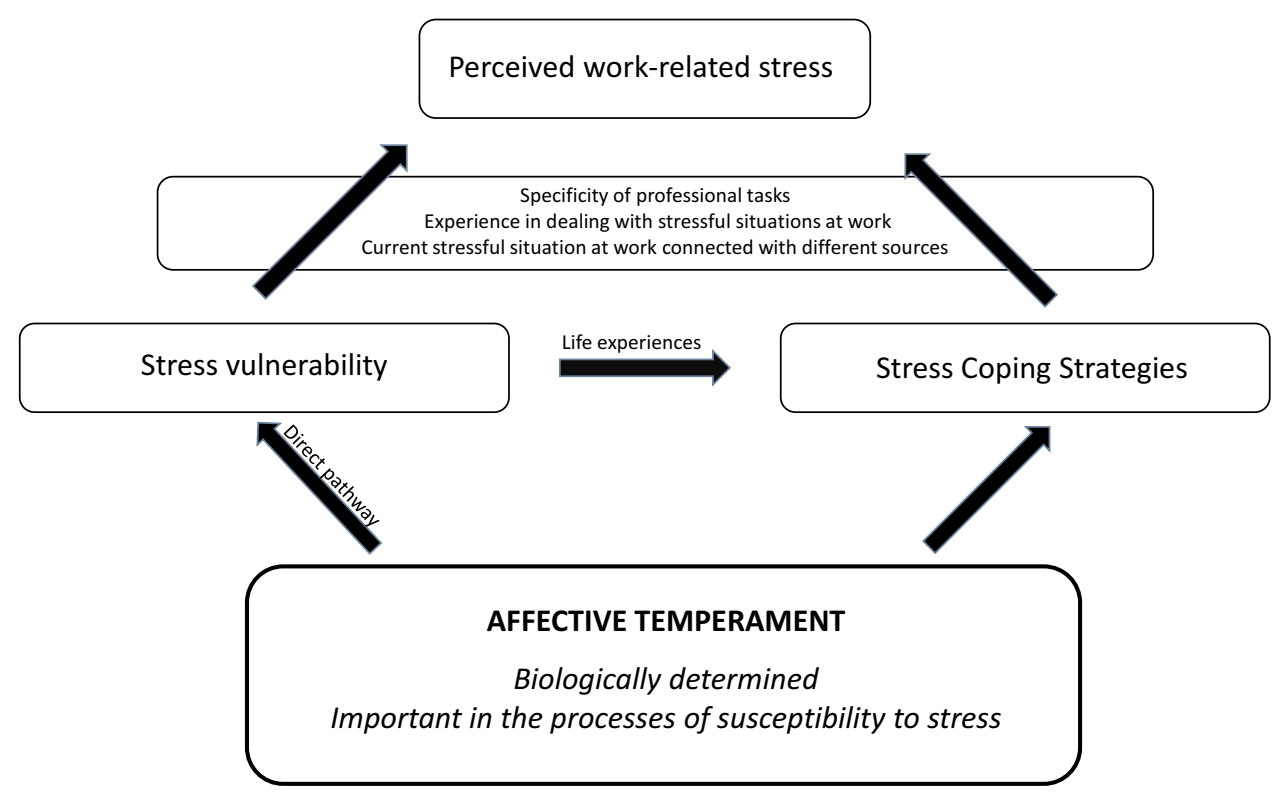

Figure 2 Model of the relationship between affective temperament, stress coping strategies and perceived work-related stress to its various sources in the surveyed bank employees.

depressive temperament predicts coping style focused on avoidance (SFA), however higher level of anxious temperament predicts lower scores on SFA. Cyclothymic temperament predicts overall level of job-related stress perception. Irritable and anxious temperament predicted coping style focused on task, however irritable dimensions predicted higher scores on SFT, while anxious ones show the opposite effect. Data obtained by Kesebir et al showed an association between irritable and anxious temperament and lower psychological resilience in healthy subjects and in depressed patients. ${ }^{37}$ Cyclothymic/irritable temperament is connected with negative affect, risky behavior, and restlessness, and with elevated stress reactivity in daily life. ${ }^{38}$ Moreover, the continuum on irritable and cyclothymic temperament increases from healthy subjects through major depressive disorder to bipolar disorder group. ${ }^{39}$ This suggests the importance of irritable temperament in the etiology of affective disorders. In this context our observation of association between higher scores on irritable temperament and style focusing on task may be interpreted as over adaptation to the work demands, which may be recognized as maladaptive behavior in those subjects, however this concept requires further exploration. Probably some of the maladaptive behaviors have functional values and may be associated with changes in environmental contingencies. ${ }^{40}$ The similar data comes from research by Japanese authors, which found, that affective temperaments explained $36 \%$ of the variance of overcommitment in a Japanese IT service company. ${ }^{41}$
Also Miyoshi et al reported that temperament dimensions could predict future depressive state and risk for future burnout in healthcare residents who never suffered from depression. ${ }^{42}$ Their data suggested that medical residents with high cooperativeness were significantly more prone to burnout than those with low cooperativeness; however, residents with high scores on harm avoidance and low scores on self-directedness, measured using the Cloninger's Temperament and Character Inventory, showed significantly higher vulnerability to depressive states. Our results may suggest that bank workers also belong to the group with high risk of burnout and job stress-related dysfunctional behaviors. Interesting results obtained by Simpson et al in a study performed in clinical psychologists, which is a group with high risk of burnout. ${ }^{43}$ The results indicated that early maladaptive schemas and specific coping modes could predict burnout syndrome. In conclusion, the results obtained indicate different levels of job-related stress associated with different sources in bank employees working in managerial and non-managerial positions. Affective temperament is associated with stress coping strategies and intensity of perceived job stress. On the basis of affective temperament dimensions it is possible to predict stress coping styles and work-related stress perception in bank employees.

The results of our study have provided meaningful insights into occupational health in financial sector workers. This could help to manage work-related stress by taking into account temperamental features of the employees. 


\section{Limitations}

The main limitation of this study was the cross-sectional study which meant that no inferral causal relationships were possible. Also the study was characterized by a significant $20 \%$ drop-out, probably due to personal questions. The study was limited to a group of employees of several banks that agreed to conduct research among their employees. This makes it difficult to generalize the results of the study, despite the fact that the study group was representative. The anonymous nature of the research meant that it was impossible to verify, in a direct conversation with employees, other sources of occupational stress other than those assumed in the study.

\section{Disclosure}

The authors report no conflicts of interest for this work.

\section{References}

1. Tuomi K, Vanhala S, Nykyri E, Janhonen M. Organizational practices, work demands and the well-being of employees: a follow-up study in the metal industry and retail trade. Occup Med. 2004;54 (2):115-121. doi:10.1093/occmed/kqh005

2. Tanaka S, Maruyama Y, Ooshima S, Ito H. Working condition of nurses in Japan: awareness of work-life balance among nursing personnel at a university hospital. J Clin Nurs. 2011;20(1-2):12-22. doi: $10.1111 / \mathrm{j} .1365-2702.2010 .03354 . \mathrm{x}$

3. Tsai SY. A study of the health-related quality of life and work-related stress of white-collar migrant workers. Int $J$ Environ Res Public Health. 2012;9(10):3740-3754. doi:10.3390/ijerph9103740

4. Vänni K, Virtanen P, Luukkaala T, Nygård C-H. Relationship between perceived work ability and productivity loss. Int J Occup Saf Ergon. 2012;18:299-309. doi:10.1080/10803548.2012.11076946

5. Silva JL, Navarro VL. Work organization and the health of bank employees. Rev Lat Am Enfermagem. 2012;20(2):226-234. doi:10. 1590/S0104-11692012000200003

6. Goetzel RZ, Long SR, Ozminkowski RJ, Hawkins K, Wang S, Lynch WL. Health, absence, disability, and presenteeism cost estimates of certain physical and mental health conditions affecting, U S Employers. J Occup Environ Med. 2004;46:398-412. doi:10.1097/01. jom.0000121151.40413.bd

7. Van Hal G. The true cost of the economic crisis on psychological well-being: a review. Psychol Res Behav Manag. 2015;8:17-25. doi:10.2147/PRBM.S44732

8. Hassard J, Teoh KR, Visockaite G, Dewe P, Cox T. The cost of work-related stress to society: a systematic review. J Occup Health Psychol. 2018;1:1-17. doi:10.1037/ocp0000069

9. Kaur K, Kaur P, Kumar P. Stress, coping mechanisms and its socioeconomic impact on organisations-A review. Indian J Econ Dev. 2017;13:744-751. doi:10.5958/2322-0430.2017.00163.9

10. Navarro A, Utzet $M$, Salas S, Llorens C, Molinero-Ruiz E, Moncada S. Specific psychosocial exposures for workers' mental health: A population-based study. Am J Ind Med. 2017;60 (8):747-752. doi:10.1002/ajim.22733

11. Giorgi G, Arcangeli G, Ariza-Montes A, Rapisarda V, Mucci N. Work-related stress in the Italian banking population and its association with recovery experience. Int J Occup Med Environ Health. 2019;32(2):255-265. doi:10.13075/ijomeh.1896.01333
12. Giorgi G, Arcangeli G, Perminiene M, et al. Work-related stress in the banking sector: a review of incidence, correlated factors, and major consequences. Front Psychol. 2017;8:2166. doi:10.3389/ fpsyg.2017.02166.

13. Mannocci A, Marchini L, Scognamiglio A, et al. Are bank employees stressed? Job perception and positivity in the banking sector: an Italian observational study. Int $J$ Environ Res Public Health. 2018;15(4):E707. doi:10.3390/ijerph15040707

14. Alarcon G, Eschleman K, Bowling N. Relationships between personality variables and burnout: A metaanalysis. Work Stress. 2009;23:244-263. doi:10.1080/02678370903282600

15. Tei-Tominaga M, Akiyama T, Sakai Y. Effect of affective temperaments assessed by the temps-a on the relationship between work-related stressors and depressive symptoms among workers in their twenties to forties in Japan. Depress Res Treat. 2012;2012:469384. doi:10.1155/2012/469384

16. Jaracz M, Rosiak I, Bertrand-Bucińska A, Jaskulski M, Nieżurawska J, Borkowska A. Professional burnout in nurses and civil servants. PLoS One. 2017;12(6):e0176698. doi:10.1371/journal.pone.0176698

17. Akiskal KK, Akiskal HS. The theoretical underpinnings of affective temperaments: implications for evolutionary foundations of bipolar disorder and human nature. J Affect Disord. 2005a;85:231-239. doi:10.1016/j.jad.2004.08.002

18. Akiskal HS, Akiskal KK. Special issue: TEMPS: temperament evaluation of Memphis, Pisa, Paris and San Diego. J Affect Disord. 2005b;85:1-242. doi:10.1016/j.jad.2004.12.003

19. Maina G, Salvi V, Rosso G, Bogetto F. Cyclothymic temperament and major depressive disorder: A study of Italian patients. $J$ Affect Disord. 2010;121:199-203. doi:10.1016/j.jad.2009.05.031

20. Mahon K, Perez-Rodriguez M, Gunawardane N, Burdick KE. Dimensional endophenotypes in bipolar disorder: affective dysregulation and psychosis proneness. $J$ Affect Disord. 2013;151 (2):695-701. doi:10.1016/j.jad.2013.08.003

21. Azorin JM, Adida M, Belzeaux R. Predominant polarity in bipolar disorders: further evidence for the role of affective temperaments. $J$ Affect Disord. 2015;182:57-63. doi:10.1016/j.jad.2015.04.037

22. Baldessarini RJ, Innamorati M, Erbuto D, et al. Differential associations of affective temperaments and diagnosis of major affective disorders with suicidal behavior. J Affect Disord. 2017;210:19-21. doi:10.1016/j.jad.2016.12.003

23. Sakai Y, Akiyama T, Miyake Y, et al. Temperament and job stress in Japanese company employees. J Affect Disord. 2005;85:101-112. doi:10.1016/j.jad.2004.03.012

24. Deguchi Y, Iwasaki S, Konishi A, et al. The usefulness of assessing and identifying workers' temperaments and their effects on occupational stress in the workplace. PLoS One. 2016;11(5):e0156339. doi:10.1371/journal.pone. 0156339

25. Lazarus RS, Folkman S. Stress, Appraisal, and Coping. New York: Springer; 1984.

26. Viana Machado A, Volchan E, Figueira I, et al. Association between habitual use of coping strategies and posttraumatic stress symptoms in a non-clinical sample of college students: A Bayesian approach. PLoS One. 2020;15(2):e0228661. doi:10.1371/journal.pone.0228661

27. McKinley N, McCain RS, Convie L, et al. Resilience, burnout and coping mechanisms in UK doctors: a cross-sectional study. $B M J$ Open. 2020;10(1):e031765. doi:10.1136/bmjopen-2019-031765

28. Fortes-Ferreira L, Peiró JM, González-Morales MG, Martín I. Workrelated stress and well-being: the roles of direct action coping and palliative coping. Scand J Psychol. 2006;47(4):293-302. doi:10.1111/ j.1467-9450.2006.00519.x

29. Borkowska A, Rybakowski JK, Drozdz W, et al. Polish validation of the TEMPS-A: the profile of affective temperaments in a college student population. $J$ Affect Disord. 2010;123:36-41. doi:10.1016/j. jad.2009.09.024

30. Strelau J, Jaworowska A, Wrześniewski K. Kwestionariusz Radzenia sobie w sytuacjach stresowych CISS. Podrecznik Do Polskiej Normalizacji Pracownia Testów Psychologicznych, Warszawa. 2009. 
31. Fountoulakis KN, Gonda X. Modeling human temperament and character on the basis of combined theoretical approaches. Ann Gen Psychiatry. 2019;17(18):21. doi:10.1186/s12991-019-0247-1

32. Russo A, Santangelo G, Tessitore A, et al. Coping strategies in migraine without aura: a cross-sectional study. Behav Neurol. 2019;5808610. doi:10.1155/2019/5808

33. Wilski M, Gabryelski J, Brola W, Tomasz T. Health-related quality of life in multiple sclerosis: links to acceptance coping strategies and disease severity. Disabil Health J. 2019;12(4):608-614. doi:10.1016/ j.dhjo.2019.06.003

34. Varela C, Andrés A, Saldaña C. The behavioral pathway model to overweight and obesity: coping strategies, eating behaviors and body mass index. Eating Weight Disorders. 2020;25(5):1277-1283. doi:10.1007/s40519-019-00760-2

35. Jaracz M, Paciorek P, Buciński A, Borkowska A. Affective temperament and executive functions in emergency medicine professionals. J Affect Disord. 2014;168:192-196. doi:10.1016/j.jad.2014.07.004

36. Rihmer Z, Akiskal KK, Rihmer A, Akiskal HS. Current research on affective temperaments. Curr Opin Psychiatr. 2010;23(1):12-18. doi:10.1097/YCO.0b013e32833299d4

37. Kesebir S, Gündoğar D, Küçüksubaşı Y, Yaylacı ET. The relation between affective temperament and resilience in depression: A controlled study. J Affect Disord. 2013;148:352-356. doi:10. 1016/j.jad.2012.12.023
38. Walsh MA, Brown LH, Barrantes-Vidal N, Kwapil TR. The expression of affective temperaments in daily life. J Affect Disord. 2013;145 (2):179-186. doi:10.1016/j.jad.2012.07.026

39. Solmi M, Zaninotto L, Toffanin T, et al. A comparative meta-analysis of TEMPS scores across mood disorder patients, their first-degree relatives, healthy controls, and other psychiatric disorders. J Affect Disord. 2016;196:32-46. doi:10.1016/j.jad.2016.02.013

40. Miller RR, Polack CW. Sources of maladaptive behavior in normal organisms. Behav Processess. 2019;154:4-12. doi:10.1016/j. beproc. 2017.12 .017

41. Tei-Tominaga M, Akiyama T, Miyake Y, Sakai Y. The relationship between temperament, job stress and overcommitment: a cross-sectional study using the TEMPS-A and a scale of ERI. Ind Health. 2009;47(5):509-517. doi:10.2486/indhealth.47.509

42. Miyoshi R, Matsuo H, Takeda R, Komatsu H, Abe H, Ishida Y. Burnout in Japanese residents and its associations with temperament and character. Asian $J$ Psychiatr. 2016;24:5-9. doi:10.1016/j. ajp.2016.08.009

43. Simpson S, Simionato G, Smout M, et al. Burnout amongst clinical and counselling psychologist: the role of early maladaptive schemas and coping modes as vulnerability factors. Clin Psychol Psychother. 2019;26(1):35-46. doi:10.1002/cpp.2328
Psychology Research and Behavior Management

\section{Publish your work in this journal}

Psychology Research and Behavior Management is an international, peer-reviewed, open access journal focusing on the science of psychology and its application in behavior management to develop improved outcomes in the clinical, educational, sports and business arenas. Specific topics covered in the journal include: Neuroscience, memory and decision making; Behavior modification and management; Clinical

\section{Dovepress}

applications; Business and sports performance management; Social and developmental studies; Animal studies. The manuscript management system is completely online and includes a very quick and fair peer-review system, which is all easy to use. Visit http://www. dovepress.com/testimonials.php to read real quotes from published authors. 